\title{
UPDATE IN DIAGNOSIS AND TREATMENT OF CRYPTOSPORIDIOSIS AN UPDATE REVIEW
}

\author{
By
}

OSAMA H. ABDALLA

Department of Medical Parasitology, Faculty of Medicine, South Valley

University, Qena, Egypt (Email:osamaabdella@yahoo.com)

\begin{abstract}
Cryptosporidiosis represents a major public health problem which transmitted by contamination of food or water by sporulated Cryptosporidial oocyst. Causing self- limited diarrhea in immunocompetent person and chronic and life threatening diarrhea among immunocompromised individuals. It can be diagnosed by concentration and detection of its Oocyst in different environmental samples and water by microscopic and immunological examination such as enzyme immunoassay (ELISA) for parasite antigens and nucleic acid amplification assay as well as use of molecular techniques such as Polymerase Chain Reaction (PCR).

Treatment is face challenges, Macrolides, Paramomycin, Nitazoxanide and Mirazid. All these drugs have partial efficacy in reducing disease severity in immunocompetent individuals. Nitazoxanide has partial efficacy in immunocompromised individuals. Resolution of Cryptosporidiosis can be maintained with effective Highly Active Antiretroviral Therapy (HAART).
\end{abstract}

Keywords: Cryptosporidosis, C. parvum, C. hominis, diarrhea, diagnosis, Treatment.

\section{Introduction}

Cryptosporidium is a globally distributed genus of protozoan parasites infecting the gastrointestinal tract of a wide range of invertebrate and vertebrate hosts, including humans (Xiao and Feng, 2008). The majority of human infections are caused by two species; the anthroponotic Cryptosporidium hominis and the zoonotic C. parvum (Waldron et al, 2010). Cryptosporidiosis causes chronic and life threatening diarrhea among immunocompromised individuals but self-limiting diarrhea in immunocompetent individuals (Banwat et al, 2004).

Cryptosporidiosis is normally initiated by ingestion of Cryptosporidium oocytes from contaminated drinking water, recreational water, Cryptosporidium is recognized as a major human waterborne pathogen worldwide (Clancy et al, 2007). Cryptosporidium is recognized as a public health issue world-wide (Yoder and Beach, 2010) whereas; Cryptosporidium sp. has been estimated at 60,000 cases per year (Bridge et al, 2010). Patients with
Acquired Immunodeficiency Syndrome (AIDS) may be susceptible to a wide range of Cryptosporidium sp. and genotypes to which an immunocompetent individual is not susceptible (Plutzer and Karanis, 2009). Diagnosis of cryptosporidiosis has progressed from histological identification in intestinal biopsies to microscopic examination of fecal specimens for infective oocysts, enzyme immunoassay for parasite antigens and nucleic acid amplification assay as well as use of molecular techniques such as Polymerase Chain Reaction (Phillip et al, 2008).

Taxonomy and Biology: Cryptosporidi$u m$ is classified within the coccidian parasites; some studies have revealed that the genus belongs to an early emerging taxonomy of the Apicomplexa, and that it is more closely related to the Gregarinia than to the Coccidia (Rosales et al, 2005). The genus Cryptosporidium is one of over 300 genera that include 4,800 named species in the phylum Apicomplexa (Fayer and Xiao, 2008). It comprises several species and genotypes which infect a 
wide range of host including humans. There is extensive genetic variation within the genus Cryptosporidium, with at least 23 species being considered valid by most investigators, these species are collectively found in human, mouse, cattle, pig, sheep, horse, goat, cat, dog, kangaroo, chicken, turkey, fish, ferrets, lizard, monkey and deer (Smith, 2008). With a few exceptions, most species and genotypes are host-adapted in nature, of these 23 species, at least 7 have been found to infect human immunodeficiency virus (HIV)-infected individuals i.e. C. parvum, C. hominis, C. meleagridis, C. felis, $C$. muris, C. canis and C. suis (Traversa, 2010). Abd El Kader et al. (2012) in Egypt by genotyping stated that Cryptosporidium hominis and $C$. parvum are the main agents of cryptosporidiosis in humans. They examined a total of $391 \mathrm{hu}-$ man faecal samples were collected, between May 2008 and March 2009, from ten public hospitals in Great Cairo. Initial screening by immunochromatographic detection kit "the Stick Crypto-Giardia; Operon" showed 23 possible positive cases. Twenty of them were confirmed by microscopic examination. PCR was performed by amplification of the oocyst wall protein (COWP) gene where 18 out of 23 samples were positive, one not detected by microscopy. Cryptosporidium genotyping was performed by RFLP analysis of PCR products of the diagnosis PCR. The genotyping distribution was nine cases showing $C$. hominis genotype, three showing $C$. parvum genotype and three showing mixed infection by $C$. hominis and $C$. parvum. They concluded that the high elevated prevalence of C. hominis (80\%), most anthroponotic species, suggesting a human-human transmission.

Mode of Transmission: Cryptosporidium seems to be a greater public health threat because of its insensitivity to disinfection regimens used in water purification leading to an increased likelihood of infectious oocysts being present in conventionally treated drinking water (Smith et al, 2006). The infection is spread to human in a number of ways: from person to person, from animals, via food, and water. Contact with other cases, foreign travel, and contact with livestock are recognized risk factors for human cryptosporidiosis (Hunter and Thompson, 2005), also sexual contact has been reported (Ghimire et al, 2004). Airborne transmission has also been postulated (Chalmers and Davies, 2010). There are fewer foodborne outbreaks documented than waterborne outbreaks (Smith et al, 2007). Cryptosporidium sp. can be transmitted from person to person and zoonotically, both directly and indirectly, through the environment (Siwilia et al, 2007). Filth flies transport infectious oocysts of $C$. parvum on their external surfaces and in their digestive tracts deposit infectious oocysts on visited foodstuff (Getachew et al, 2007).

Epidemiologic pictures: The broad range in prevalence of cryptosporidiosis may be attributed to many causes as immune state of the patients, patient's age, environmental habitats or seasonal variation (Derouin et al, 2010). Human cryptosporidiosis was also reported in different ages whereas; prevalence of Cryptosporidium infection in Egyptian patients varied significantly from $0 \%$ to $47 \%$, it is a common cause of severe diarrhea among the Egyptian children (Youssef et $a l, 2008)$ as zoonosis from farm animals (Amer and Harfoush, 2010). The risk of infection may be high and the disease probably exerts most of its impact on neonates and infants (Hunter et al, 2009). It has been the cause of multiple diarrhea outbreaks in developed and developing countries ( $\mathrm{Ng}$ et al, 2010). The human immunodeficiency virus (HIV), and the acquired immunodeficiency syndrome (AIDS) patients have been reported to have high prevalence of cryptosporidiosis 
(Zaidah et al, 2008). In most countries studied, C. parvum and C. hominis are responsible for greater than $90 \%$ of human cases of cryptosporidiosis, with the balance attributable to $C$. meleagridis, $C$. canis and C. felis (Xiao and Fayer, 2008).

On the other hand, Sponseller et al. (2014) reported that Cryptosporidium oocysts may occur by inhalation of aerosolized droplets or by contact with fomites contaminated by coughing. They concluded that delineating the role of the respiratory tract in disease transmission may provide necessary evidence to establish further guidelines for prevention of cryptosporidiosis.

Life cycle and Morphology: Cryptosporidium has a complex life cycle including both sexual and asexual reproductive stages (Thompson et al, 2005). All species of Cryptosporidium undergo endogenous development, resulting in the production of an encysted stage discharged in the faeces of their host (Fayer et al, 2000). After being ingested, the oocysts excyst in the small intestine, they release sporozoites that attach to the microvilli of the epithelial cells of the small intestine. From there they become trophozoites (Borowski et al, 2008) that reproduce asexually by the multiple fission the process known as schizogony. The trophozoites develop into Type 1meront that contain 8 daughter cells, which get released by the meronts, can cause autoinfection by attaching to epithelial cells. Others of these merozoites become Type II meronts, which contain 4 Type II merozoites, these merozoites get released and they attach to the epithelial cells. From there they become either macrogamonts or microgamonts (Chen et al, 2003). These are the female and male sexual forms, respectively. This stage, when sexual forms arise, is called gametogony, the microgamont penetrating the macrogamonts producing zygotes which develop into oocysts, $20 \%$ of oocysts have thin walls and so can reinfect the host by rupturing and releasing sporozoites that start the process over again. The thick-walled oocysts are excreted into the environment. The oocyst is mature and infective upon being excreted. They can survive in the environment for months (Fayer, 2008).

Pathogenesis and immunology: The mechanism by which Cryptosporidium infection causes diarrhea remains unclear, whatever the mechanisms by which Cryptosporidium infection causes disease may be, attachment to and invasion of host cells are crucial primary events in pathogenesis (Tzipori and Ward, 2002). The parasite does elicit a local inflammatory response, and increased production of prostaglandins and several cytokines, particularly The Interferons as IFN-Y, has been described, where these inflammatory mediators may consequently alter solute transportation in the intestinal epithelial cell, leading to osmotic diarrhea (Singh et $a l, 2005)$. Both innate and adaptive immunity are involved in the resolution of cryptosporidiosis and resistance to infection (Thompson et al, 2005). The invasion of intestinal and biliary epithelial cells by C. parvum in vitro activates epithelial cells, resulting in the production and secretion of various cytokines and chemokines and anti-microbial peptides (e.g., $\beta$ defensins and cathelicidins) that can kill C. parvum or inhibit parasite growth (Barakat et al, 2009). The alterations in miRNA expression profiles in cultured human biliary epithelial cells following $C$. parvum infection have been characterized importantly; miRNA-mediated post-transcriptional gene regulation may regulate expression of genes critical to epithelial anti-microbial defence (Zhou et al, 2009).

Clinical picture: Cryptosporidium has become one of the most commonly reported enteric pathogens in immunocompetent and immunocompromised person worldwide (Meinhardt et al, 1996).

Clinical features in immunocompetent 
people: Cryptosporidiosis is an acute selflimiting gastoenteritis in immunecompetent humans which occurs worldwide, and in all age groups, although children especially those under 2 years old are most frequently and severely affected (Chen et al, 2002). Cryptosporidium sp. infects intestinal or respiratory epithelial cells resulting in self-limiting diarrhea or pulmonary cryptosporidiosis in immunocompetent persons (Xiao and Feng, 2008).

Clinical features in immunocompromised people: Patients with T-cell immune deficiency are at most risk, including those with haematological malignancies (particularly children), and Human Immunodeficiency virus (HIV) patients with cluster of differentiation (CD4+) lymphocyte counts more than $50 / \mathrm{mm}^{3}$, the groups of high-risk patients frequently experience chronic or intractable disease, the other symptoms include abdominal cramps, anorexia, nausea, vomiting, fatigue and low-grade fever. In such patients, in addition to typical but severe intestinal disease, atypical and extraintestinal disease can also develop. Patients can have chronic watery diarrhea that can last more than 2 months and shed oocysts in the stool during the entire period, resulting in severe dehydration, weight loss and malnutrition, extended hospitalizations and mortality (Abubakar et al, 2007). Adamu et al. (2014) in Ethiopis stated that cryptosporidiosis is an important cause for chronic diarrhea and death in HIV/AIDS patients and that infection was associated with the occurrence of diarrhea and vomiting. Diarrhea was attributable mostly to C. parvum subtype family IIa and $C$. hominis, whereas vomiting was largely attributable to $C$. hominis and rare Cryptosporidium species. Calf contact was identified as a significant risk factor for infection with Cryptosporidium spp., especially C. parvum subtype family IIa. They concluded that $C$. parvum is a major cause of cryp- tosporidiosis in HIV- positive patients and zoonotic transmission is important in cryptosporidiosis epidemiology

The AIDS patients with cryptosporidiosis most commonly have acute or subacute onset of watery diarrhea, which may be accompanied by nausea, vomiting, and lower abdominal cramping. Severity can range from the asymptomatic to profuse, cholera-like diarrhea. More severe symptoms tend to occur in immune-suppressed patients, whereas transient diarrhea alone was typical in hosts with competent immune systems. Fever was present in approximately one-third of patients and malabsorption was common. The epithelium of the biliary tract and the pancreatic duct could be infected with Cryptosporidium, leading to sclerosing cholangitis and to pancreatitis secondary to papillary stenosis, particularly among patients with prolonged disease and low CD4 cell counts (De Souza et al, 2004). Pulmonary infections also have been reported may be under-recognized (Mercado et al, 2007).

Diagnosis of cryptosporidiosis: Diagnosis of Cryptosporidiosis has progressed from histological identification in intestinal biopsies to microscopic examination of feacal specimens for infective oocysts, enzyme immunoassay (EIA) for parasite antigens and nucleic acid amplification assay as well as use of molecular techniques such as PCR (Phillip et al, 2008). In the majority of modern clinical laboratories in developed countries, the most widely used staining method for the detection of relatively low numbers of Cryptosporidium is still immunofluorescence assay (IFA) (Sunnotel et al, 2006). It is often necessary to use an oocyst concentration technique such as Immunomagnetic separation (IMS)-recovered oocysts to maintain an acceptable level of assay sensitivity (Miller et al, 2006).

Microscopy: Microscopy method involves concentration of the samples and staining to obtain accurate diagnosis 
which achieved by detecting the presence of oocysts, the environmentally resistant forms, in stool samples, mucus, and biliary samples or by determining one of the different stages of Cryptosporidium in a biopsy of intestinal tissue (Berger, 2006).

Immunological-based detection methods: Application of these genetic tools has led to enhance knowledge and understanding of systematics, biology, epidemiology, ecology and population genetics of Cryptosporidium sp., improving the strategies for the prevention, surveillance and control of cryptosporidiosis in humans and other animals (Smith et al, 2006).

1- Immunofluorescence assay (IFA): IFA procedures that employ Cryptosporidium-specific polyclonal or monoclonal antibodies is developed to aid in the identification of oocysts in stool and environmental samples (Garcia et al, 1997). Antibodies specific to Cryptosporidium have been detected, using immunofluorescent assay (IFA) procedure, in sera obtained from persons who recovered from confirmed infections, it is important since it can be done in combination with membrane exclusion / permeability dyes to estimate oocysts viability (Campbell and Current, 1998). IFA technique is not required to distinguish between $C$. parvum oocyst and non-C. parvum oocysts, it is time consuming, allows only few samples to be examined per day, and the necessity for an expert or experienced personnel to interpret the results that may not be available, (Nair et al, 2008).

2- Enzyme immunoassay (antigen detection): These enzyme immunoassays have become widely accepted as methods for screening stool samples to detect Cryptosporidium and other parasitic organisms (Pieniazek et al, 2002). It is developed to detect the antigens of Cryptosporidium species (Shimizu et al, 2000). The detection of Cryptosporidium antigens in faecal samples (coproantigens) is another diagnostic approach. Sensitivity of coproantigen detection can be lower than most microscopic approaches (Johnston et al., 2003). Some coproantigen detection assays have advantages over microscopy in that they can detect (prepatent) infections in animals not excreting oocysts in faeces (Smith and Nichols, 2007), and can be employed for the rapid and cost-effective screening of large numbers of faecal samples (Garcia et al, 2003). However, like other immunological methods, they do not allow the species or genotype of Cryptosporidium involved in the infection to be determined. The expensive nature of the enzyme immunoassay kits used for ELISA places them above the reach of many laboratories in developing countries and this may decrease their routine usage in diagnostic services (Miller et al, 2006).

3- PCR based method: Genetic method for detecting Cryptosporidium oocysts has recently been developed; the method identifies and amplifies Cryptosporidium nucleic acid using PCR (Abe et al, 2002). With Integration of flow cytometry, dot blot and magnetic antibody methods could improve the sensitivity of the PCR assay (Dixon et al, 2002), PCR is sensitive and has the potential for accurate diagnosis in patients who do not presently know the cause of their diarrhea (Oyibo et $a l, 2011)$, this could have considerable advantage in the treatment of immunosuppressed individuals, allowing for early diagnosis before the onset of symptoms.

A nested PCR assay was developed for detection of $C$. parvum oocysts directly from stool specimens by using a nested primer, this test can detect few oocysts ranging from asymptomatic infections to monitoring response to therapy for clinical as well as the environmental samples (Semenza and Nicholas, 2007). PCR followed by restriction fragment length polymorphism (RFLP) analysis or sequencing has been widely employed. PCR- 
based techniques employing specific primer pairs for the selective amplification of different genetic loci, followed by enzymatic cleavage or sequencing, have been used to characterize and classify Cryptosporidium species or "genotypes" (Xiao et al, 2004). Some key markers (loci) provide a useful genetic marker for the specific identification of Cryptosporidi$u m$, having relatively low intraspecific and relatively high interspecific sequence variation (Jex et al, 2007). PCR cannot, however, be used for routine diagnosis of Cryptosporidium oocysts due to several challenges. These include its technical complexity and interference of results by inhibitors, its expensive nature, and timeconsuming procedures (Gatei et al, 2006).

Concentration techniques for detection of oocysts in water: These methods have been designed specifically to concentrate and identify oocysts in water samples and rely typically on filtration for oocyst concentration, oocyst purification by Immuno-magnetic separation and detection using a direct fluorescent antibody method and/or Nomarski differential interference contrast microscopy for confirmation (Medema et al, 2006).

a. Flow cytometry method: Flow cytometry is a laser-based instrument that analyzes particles in a liquid suspension on a particle by- particle basis, it can differentiate and physically separate particles based on their size, internal complexity and fluorescence (Oyibo et al, 2011). More recently, flow cytometric methods have relied on the immuno-magnetic separation based (IMS) purification of oocysts over filtration/flotation approaches (Hsu et al., 2005), thus providing a significant advance in the rapid screening of environmental samples for Cryptosporidium and rapid quantification of oocysts.

b. Immunomagnetic separation (IMS): IMS concentrates Cryptosporidium oocysts by using a magnetic bead coated with an anti- Cryptosporidium antibody but the efficiency of the IMS method could be decreased in highly turbid water samples so its use is limited (Fontaine and Guillot, 2003).

c. Fluorescence activated cell sorter (FACS): The use of fluorescence microscopy and the direct fluorescent antibody (DFA) assay using a fluorescein isothiocyanate-conjugated anti-Cryptosporidium monoclonal antibody (FITC-C-mAb), which recognises surface epitopes on oocysts, has been reported to achieve relatively high specificities $(96-100 \%)$ and sensitivities (98.5-100\%) for the detection of Cryptosporidium oocysts in faecal smears and environmental samples Commercially available a fluorescein isothiocyanate-conjugated anti-Cryptosporidium monoclonal antibody (FITC-C-mAb), among which $\operatorname{IgM}$ is used routinely for detecting and enumerating oocysts or fecal samples (Smith et al, 2007).

d. Fluorescent in situ hybridization (FISH): Most FISH assays for Cryptosporidium oocysts rely on the hybdridization to RNA (rather than to DNA), targeting a variable region of the small subunit (SSU) of the nuclear ribosomal RNA (Bednarska et al, 2007). FISH was not capable of accurately determining viability, where the extent to which such FISH probes are useful for studies of oocyst viability is dependent on the rate at which small subunit (SSU) rRNA decays, and the rate of degradation will vary depending on different environmental conditions i.e., temperature, $\mathrm{pH}$, salinity and/or RNase contamination present (Smith et al, 2004).

e. Electrophoretic mutation scanning: The approaches include mutation scanning methods, such as heteroduplex analysis, temperature gradient gel electrophoresis (TGGE), denaturing gradient gel electrophoresis (DGGE) and single strand conformation polymorphism (SSCP) SSCP is a particularly useful approach in that it relies on the principle that the electropho- 
retic mobility of a single-stranded deoxyribonucleatide acid (DNA) molecule in a non-denaturing gel is highly dependent on its size and structure (conformation) and offers the capability of detecting single point mutations in amplicons of $<500 \mathrm{bp}$ (Gasser et al, 2006 ). PCR-based SSCP has proven to be a powerful tool for the identification of Cryptosporidium species or genotypes, to screen for genetic variability within and among large numbers of samples, and, importantly, to screen for unknown mutations (Jex et al, 2007).

Treatment: No drug or drug combination effectively treats Cryptosporidiosis in humans. Clinical trials have examined the efficacy of Macrolides, Paramomycin, and Nitazoxanide in reducing disease severity in immunocompetent individuals (Mor and Tzipori, 2008). Only Nitazoxanide has partial efficacy in immunocompromised individuals (Tandon and Gupta, 2014). Resolution of cryptosporidiosis was maintained with effective highly active antiretroviral therapy; HAART (Zardi et al, 2005).

Massoud et al. (2008) in Egypt reported that sixty cryptosporidiosis patients from Mansoura University Hospitals, 36 males and 24 females, with the age from few months to ten years (mean age 6.1) were divided into three cross-matched groups of 20 patients each. All patients received the glutamine-based oral rehydration solution with $111 \mathrm{mmol} / \mathrm{l}$ glutamine, $20 \mathrm{mg}$ zinc acetate once a day and vitamin $\mathrm{A}$ supplementation $(200,000 \mathrm{IU})$ once a day for 2 weeks. For cryptosporidiosis treatment, G1 received Mirazid $(10 \mathrm{mg} / \mathrm{kg}$ for 2 weeks), G2 received Paromomycin (500 $\mathrm{mg}$ qid for 2 weeks), and G3 received a combination of Mirazid $(10 \mathrm{mg} / \mathrm{kg})$ and Paromomycin $(500 \mathrm{mg}$ ) for two weeks. The result was assessed according to the scales: $0=$ no improvement, $1=$ symptoms began improvement (reduction of diarrhea frequency and stool volume, less abdominal pain, less nausea \& vomiting),
$2=$ diarrhea eradication, $3=$ weight gain, $4=$ oocyst counts reduction, $5=$ reduction in diarrhea and oocyst counts, $6=$ eradication of diarrhea \& oocysts. G3 showed significantly higher difference than G1 \& $\mathrm{G} 2$ in the 1st week ( $\mathrm{p}=.036,0.025$ respectively), no significant difference in 2nd week, a significantly higher difference than in G1 (0.003), \& G2 (0.006) in 3 rd week, and a significantly higher difference than G1 (0.014), \& G2 (0.01) in 4 th week, but without significant differences in oocyst shedding in the 3 groups.

Also, Hussien et al. (2013) in Egypt reported that ninety children infected with C. parvum at Assuit Al-Azhar University Hospitals were chosen (60 males \& 30 females) with age range from 6 months to ten years were divided into two groups of 45 patients for each $(\mathrm{G} 1 \& \mathrm{G} 2)$. All patients suffered from chronic diarrhea for more than fifteen days. Cross-matched 45 children suffering from chronic diarrhea were used as a control group (G3). Stool samples were collected and examined for detection of Cryptosporidium oocysts using Sheather's sugar and Modified ZiehlNelseen stain techniques. The first group (G1) received Nitazoxanide (100 $\mathrm{mg}$ and $200 \mathrm{mg}$ every 12 hours for 3 days for children aged 6 months to 3 years and chil dren aged 4 to 10 years respectively), G2 received Paromomycin $(25 \mathrm{mg} / \mathrm{kg} /$ day for 2 weeks). Third group received placebo. Significant improvement and shortening of the duration of diarrhea occur in G1; of 45 patients received Nitazoxanide 39 cases showed complete clinical and laboratory cure $(86.6 \%), 5$ cases showed clinical improvement with reduction in the number of oocysts and 1 case showed no cure. In $\mathrm{G} 2$ of 45 cases received Paromomycin 31 cases showed complete cure $(68.8 \%)$, 8 cases showed clinical improvement with reduction of oocysts number and 6 cases were not cured. Nitazoxanide proved highly effective than Paromomycin in cryptosporidiosis. 
1- General measures and medication: The majority of immunocompetent individuals suffer a short (less than 2 weeks) selflimiting course that requires supportive care with rehydration and occasionally antidiarrhoeal medication and ends with spontaneous recovery (Xian-ming et al, 2002).

In immunocompromised individuals, as AIDS patients, Cryptosporidiosis resolves slowly or not at all, and frequently causes a particularly severe and permanent form of watery diarrhea coupled with a greatly decreased ability to absorb key nutrients through the intestinal tract, this result in progressively severe dehydration, electrolyte imbalances, malnutrition, wasting, and eventual death (Murray et al, 2005). The severity of Cryptosporidiosis depends on the immune state of the host (Woods and Upton, 1998). In HIV-AIDS people's management require antiretroviral and anti-parasitic drugs with fluid and electrolyte therapy (Masur et al, 2008).

2-Passive immunotherapy: Passive immunotherapy has been reported to reduce the severity of Cryptosporidium infection .Several approaches have been investigated, including the use of bovine colostrums and colostral antibodies (hyperimmune and natural), monoclonal or polyclonal antibodies and lectins specific for certain glycoproteins on the surfaces of sporozoites, merozoites or oocysts, antigens associated with parasite motility, attachment and invasion of the host cell represent opportune targets for passive immunization against $C$. parvum (Riggs et al, 2002).

3-Possible use of sporozoite-specific lectins: Lectins are carbohydrate-binding plant proteins which are believed to mediate cell-to-cell interactions, including interactions between host and parasite, Keusch et al. (1995) identified a sporozoite-specific lectin adherence factor as the cause of sporozoite attachment to the intestinal surface.

4-Probiotic treatment: Probiotics, also termed biotherapeutic agents, are live microbial supplements which beneficially affect the host by improving its intestinal microbial balance; they have also been shown to limit $C$. parvum infection in immunocompromised individuals in animal models (Alak et al, 1999). Probiotics have been used successfully in treatment of acute diarrhoea and also in preventing antibiotic induced diarrhea (D'Souza et al, 2002).

5-Treatment of drinking water: The realization that Cryptosporidium oocyst are resistant to many chemical disinfectants led to a search for methods that can inactivate oocysts without generating harmful by products (Rochelle et al, 2005). Ultraviolet light treatment at relatively low doses will inactivate Cryptosporidium this is approved by Water Research Foundation-funded research which discovered UV's efficacy in inactivating Cryptosporidium (Murray et al, 2005).

6- Vaccination: Mead (2014) stated that vaccine development or immunotherapy that prevents disease or reduces the severity of infection is a relevant option since efficacious drug treatments are lacking. In particular, children in developing countries might benefit the most from a vaccine since cryptosporidiosis in early childhood has been reported to be associated with the subsequent impairment in growth, physical fitness, and intellectual capacity. In this review, immunotherapies that have been used clinically are described as well as experimental vaccines and their evaluation in vivo. Eladl et al. (2014) studied the consequence of cryptosporidiosis on the immune response of vaccinated chickens against Newcastle disease and/or avian influenza was studied. They found that H5N2 vaccine at day 10 of chicken life is effective in chickens indicated by the geometric mean of HI titer against AI virus. The findings of this study showed that the infection with Cryptosporidia in the broiler chicken has 
a depressive effect on the immune status of the birds vaccinated against ND and/or AI vaccination. Moreover, the obtained protection rates against challenge with virulent ND virus observed to be parallel to the results of HI- test. Also, by using 2 different antigens (one commercial and field prepared antigen) to avian influenza virus, lower Geometric mean (GM) HI titer were appeared in infected and vaccinated group than vaccinated group only. A study of the relative lymphoid organs weight such as bursa of Fabricius from the experimental chicks indicated that those organs were comparable between the groups infected-vaccinated and vaccinated only. Non-significant variations in final live weight between uninfected control and infected groups were indicated. Also, H5N2-AI vaccination at 10 days old did not affect the final live weight. ND and/or AI Vaccination could not be a substitute to application of good hygienic measures and fecal examination of the birds especially for protozoal diseases such as cryptosporidiosis. It could be concluded that cryptosporidiosis could be one cause of ND and/or AI vaccination failure in poultry farms.

\section{Conclusion}

Cryptosporidiosis is a real zoonotic worldwide problem particularly among children can be diagnosed by detection of its oocysts in the different environmental specimens using microscopic or immunological or molecular based examination also by using different concentration techniques to water oocysts.

But its treatment face challenges due to the lack of adequate drug or drug combination. Many of drugs have been tested, including Paromomycin, Mirazid with or without Paromomycin, Macrolides (as Azithromycin and Spiramycin) \& Albendazole, are partially effective. Nitazoxanide is used to treat cryptosporidiosis in HIV-infected patient and the Antiretroviral therapy (ART) which greatly influences the outcome of cryptosporidiosis.

\section{References}

Abd El Kader, NM, Blanco, MA, Ali, TM, Abd El Ghaffar, Ael R, Osman, A, 2012: Detection of Cryptosporidium parvum and Cryptosporidium hominis in human patients in Cairo, Egypt. Parasitol. Res. 110, 1: 161-6. Abe, N, Kimata, I, Iseki, M, 2002: Comparative study of PCR-based Cryptosporidium discriminating techniques. J. Parasitol. 10: 869-81.

Abubakar, I, Aliyu, SH, Arumugam, C, et al, 2007: Treatment of Cryptosporidiosis in immunocompromised individuals: systematic review and meta-analysis. Br. J. Clin. Pharmacol, 4:387-93.

Adamu, H, Petros, B, Zhang, G, Kassa, H, Amer, S, et al, 2014: Distribution and clinical manifestations of Cryptosporidium species and subtypes in HIV/AIDS patients in Ethiopia. PLoS. Negl. Trop. Dis. Apr 17;8 (4):e2831.doi:10.1371/journal.pntd. 0002831. Alak, JI, Wolf, BW, Mdurvwa, EG, et al, 1999: Supplementation with Lactobacillus reuteri or $L$ acidophilus reduced intestinal shedding of Cryptosporidium parvum oocysts in immunodeficient C57BL/6 mice. Cell Mol. Biol. 45:855-63.

Amer, S, Harfoush, M, 2010: Molecular and phylogenetic analyses of Cryptosporidium spp. from dairy cattle in Egypt. J. Egypt. Soc. Parasitol. 40, 2:349-66.

Banwat, E.B., Egah, DZ, Audu, ES, et al, 2004: Cryptosporidium infection in under nourished children with HIV/AIDS inJos, Nigeria. Ann. Afri. Med. 2:80-2.

Barakat, FM, McDonald, V, Foster, GR, et al, 2009: Cryptosporidium parvum infection rapidly induces a protective innate immune response involving type I interferon. J. Infect. Dis. 20:1548-55.

Bednarska, M, Bajer, A, Sinski, E, et al, 2007: Fluorescent in situ hybridization as a tool to retrospectively identify Cryptosporidium parvum and Giardia lamblia in samples from terrestrial mammalian wildlife. Parasitol. Res. 100:455-60.

Berger, SA, 2006: Human Parasitic Diseases Source-Book. Jones and Bartlett, Massachusetts, USA.

Borowski, H, Clode, PL, Thompson, RCA, 
2008: Active invasion and/or encapsulation? A reappraisal of host-cell parasitism by Cryptosporidium. Trends Parasi-tol. 24:509-16.

Bridge, JW, Oliver, DM, Chadwick, D, et al, 2010: Engaging with the water sector for public health begets: waterborne pathogens and diseases in developed countries. Bull. WHO 88:797-876.

Campbell, PN, Current, WL, 1998: Demonstration of serum antibodies of Cryptosporidium spp in normal and immune-deficient human with confirmed infections J. Clin. Microbiol.18:165-9.

Chalmers, RM, Davies, AP, 2010: Mini review: Clinical cryptosporidiosis. Exp. Parasitol. 124:138-46.

Chen, W, Harp, JA, Harmsen AG, 2003: Cryptosporidium parvum infection in genetargeted B cell-deficient mice. J. Parasitol. 2: 391-3.

Chen, XM, Keithly, JS, Paya, CV, et al, 2002: Cryptosporidiosis. N. Engl. J. Med. 346:1723-31.

Clancy, JL, Hargy, TM, Fayer, R, Xiao, L, et al, 2007: Waterborne: Drinking water. In: Cryptosporidium and Cryptosporidiosis. Boca Raton, FL: CRC Press.

D'Souza, AL, Rajkumar, C, Cooke, J, et al, 2002: Probiotics in prevention of antibiotic associated diarrhoea: meta-analysis. BMJ. 24: 1361-4.

De Souza, Ldo R, Rodrigues, MA, Morceli, J, Kemp, R, Mendes, RP, 2004: Cryptosporidiosis of the biliary tract mimicking pancreatic cancer in an AIDS patient. Rev. Soc. Bras. Med. Trop. 37, 2:182-5.

Derouin, F, Dutoit, E, de Monbriso, F, 2010: Cryptosporidium National Network Laboratory-based surveillance for Cryptosporidium in France, 2006-2009. Euro Surv. 33:239.

Dixon, BR, Fayer, R, Parrington, M, 2002: Cryptosporidiosis surveillance and water borne outbreaks in Europe. Euro Surv. 12:611711.

Eladl, AH, Hamed, HR, Khalil, MR, 2014: Consequence of Cryptosporidiosis on the immune response of vaccinated broiler chickens against Newcastle disease and/or avian influenza. Vet. Res. Commun. 2014 Jul 5. [Epub ahead of print]

Fayer, R, 2008: General Biology and Cryptosporidium and Cryptosporidiosis, Taylor and Francis Group, CRC Press, Boca Raton, London, New York.

Fayer, R, Morgan, U, Upton, SJ, 2000: Epidemiology of Cryptosporidium: transmission, detection and identification. Int. J. Parasitol. 30:1305-22.

Fayer, R, Xiao, L, 2008: General Biology and Cryptosporidium and Cryptosporidiosis, CRC Press and IWA Publishing, Boca Raton.

Fontaine, KL, Guillot, JA, 2003: Threshold of detection of Cryptosporidium oocysts in human stool specimens: evidence for low sensitivity of current diagnostic methods. J. Clin. Microbiol. 29:1323-30.

Garcia, LS, Shimizu, RY, Bruncker, SR, 1997: Evaluation of nine immunoassay kits (enzyme immunoassay and direct fluorescence) for detection of Giardia lamblia and Cryptosporidium parvum in human fecal specimens. J. Clin. Microbiol. 35:1526-9.

Garcia, LS, Shimizu, RY, Novak, S, et al, 2003: Commercial assay for detection of $\mathrm{Gi}$ ardia lamblia and Cryptosporidium parvum antigens in human fecal specimens by rapid solid-phase qualitative immunochromatography. J. Clin. Microbiol. 41:209-12.

Gasser, RB, Hu, M, Chilton, NB, et al, 2006: Single-strand conformation polymorphism (SSCP) for the analysis of genetic variation. Nature Protoc. 1:3121-8.

Gatei, MH, Hayes, EB, Matte, TD, et al, 2006: Large community outbreak in Milwaukee of Cryptosporidium infection transmitted through the public water supply N. Engl. J. Med. 331:161-7.

Getachew, S, Gebre, T, Erko, B, et al, 2007: Non-biting cyclorrhaphan flies (Diptera) as carriers of intestinal human parasites in slum, areas of Addis Ababa, Ethiopia. Acta. Trop. 103:186-94.

Ghimire, P, Sapkota, D, Manandhar, SP, 2004: Cryptosporidiosis: opportunistic infection in HIV/AIDS patients in Nepal. J. Trop. Med. Parasitol. 27:7-10.

Hsu, BM, Wu, NM, Jang, HD, et al, 2005: Using the flow cytometry to quantify the Giardia cysts and Cryptosporidium oocysts in water samples. Environ. Monit. Assess. 104: 155-62.

Hunter, PR, Thompson, RCA, 2005: The zoonotic transmission of Giardia and Cryptosporidium. Int. J. Parasitol. 35:1181-90.

Hunter, PR, Zmirou, D, Hartemann, P, 
2009: Estimating the impact on health of poor reliability of drinking water interventions in developing countries. Sci. Total Environ. 8: 2621-4.

Hussien, SM, Abdella, OH, Abu-Hashim, A H, Aboshiesha, GA, Taha, MA, et al, 2013: Comparative study between the effect of nitazoxanide and paromomycine in treatment of cryptosporidiosis in hospitalized children. J. Egypt. Soc. Parasitol. 43, 2:463-70.

Jex, AR, Whipp, M, Campbell, BE, et al, 2007: A practical and cost effective mutation scanning-based approach for investigating genetic variation in Cryptosporidium. Electrophoresis 28:3875-83.

Johnston, SP, Ballard, MM, Beach, MJ, et al, 2003: Evaluation of three commercial assays for detection of Giardia and Cryptosporidium organisms in fecal specimens. J. Clin. Microbiol. 41:623-6.

Keusch, G, Hamer, D, Kelley, M, et al, 1995: Cryptosporidia-who is at risk? Schweiz. Med. Wochenschr. 18:899-908.

Massoud, AM, Hafez, AO, Abdel-Gawad, AG, El-Shazly, AM, Morsy, TA, 2008: Mirazid alone or combined with Paromomycin in treating cryptosporidiosis parvum in immmunocompetent hospitalized patients. J. Egypt. Soc. Parasitol. 38, 2:399-418.

Masur, H, Kaplan, KJ, Holmes, KK, et al, 2008: Adult prevention and treatment of opportunistic infection guideline working group: Guideline for Prevention and treatment of opportunistic infection in HIV-infected adult and adolescents. Deveoplment of health \& human Services 22, 11:1345-54.

Mead, JR, 2014: Prospects for immunotherapy and vaccines against Cryptosporidium. Hum Vaccin Immunother. 2014 Mar 17; 10 (6). [Epub ahead of print]

Medema, G, Teunis, P, Blokker, M, et al, 2006: WHO Guidelines for Drinking Water Quality: Cryptosporidium. WHO, Geneva.

Meinhardt, PL, Casemore, DP, Miller KB, 1996: Epidemiologic aspects of human Cryptosporidiosis and the role of waterborne transmission. Epidemiol. Rev. 18:118-36.

Mercado, R, Buck, GA, Manque, PA, Ozaki, LS, 2007: Cryptosporidium hominis infection of the human respiratory tract. Emer. Infect. Dis. 13, 3:462-464.

Miller, WA, Gardner, I, Atwill, ER, et al, 2006: Evaluation of methods for improved detection of Cryptosporidium spp. in mussels (Mytilus californianus). J. Microbiol. Methods 65:367-79.

Mor, MS, Tzipori, S, 2008: Cryptosporidiosis in children in Sub-Saharan Africa: Lingering. Clin. Infect. Dis. 7:15-21.

Murray, PR, Rosenthal, KS, et al, 2005: Medical Microbiology. Philadelphia: Elsevier Inc. 5:855-6.

Nair, P, Mohammed, JA, Herbert, L, et al, 2008: Epidemiology of cryptosporidiosis in North America Travelers to Mexico. Am. J. Trop. Med. Hyg. 2:210-4.

Ng, JS, Pingault, N, Gibbs, R, et al, 2010: Molecular characterization of Cryptosporidium outbreaks in Western and South Australia. Exp. Parasitol. 4:325-8.

Oyibo, WA, Okangba, CC, Obi, RK, et al, 2011: Challenges in diagnosis of cryptosporidiosis in Africa. Nigeria J. Appl. Biosci. 40:2659-67.

Phillip, JL, Rebecca, CL, Robinson, M, et al, 2008: Cryptosporidium muris in Texas cainin population. Am. J. Trop. Med. Hyg. 6:917-21.

Pieniazek, NJ, da Silva, AJ, Moura, IN, et al, 2002: New Cryptosporidium genotypes in HIV infected persons. Emer. Infect. Dis. 5:444-9.

Plutzer, J, Karanis, P, 2009: Genetic variation in Cryptosporidium. Vet. Parasitol. 165: 187-99.

Riggs, MW, Schaefer, DA, Kapil, SJ, et al, 2002: Efficacy of monoclonal antibodies against defined antigens for passive immunotherapy of chronic gastrointestinal cryptosporidiosis, Antimicrob. Agents Chemother. 46:275-82.

Rochelle, PA, Upton, SJ, Montelone, BA, et al, 2005: The response of Cryptosporidium parvum to UV light. Trends. Parasitol. 2:81-7. Rosales, MJ, Peréz, G, SInchez, M, et al, 2005: Extracellular like-gregarine stages of Cryptosporidium parvum. Acta. Trop. 95:748.

Semenza, JC, Nicholas, G, 2007: Cryptosporidiosis surveillance and waterborne outbreaks in Europe Euro. Surv. 12:611-711.

Shimizu, SRJ, Deckelbaum, II, Schmid, S, Harlap, MB, Spora, DT, 2000: Cryptosporidium, nutrition, and chronic diarrhea in children. Am. J. Dis. Child. 142:312-5.

Singh, I, Theodos, C, Li, W, et al, 2005: Ki- 
netics of Cryptosporidium parvum-specific cytokine responses in healing and nonhealing murine models of $C$. parvum infection. Parasitol. Res. 97:309-17.

Siwilia, J, Phiri, IG, Vercruysse, J, et al, 2007: Asymptomatic Cryptosporidiosis in Zambian dairy farm workers and their household members. Trans. R. Soc. Trop. Med. Hyg.7:733-4.

Smith HV, 2008: Cryptosporidiosis. In: OIE Biological Standards Commission (Eds.), OIE Manual of Diagnostic Tests and Vaccines for Terrestrial Animals: Office International des Epizooties, Rue de Prony, Paris, France.

Smith, HV, Cacciò, SM, Cook, N, Nichols, RA, Tait, A, 2007: Cryptosporidium and Giardia as foodborne zoonoses. Vet. Parasitol. $149,1 / 2: 29-40$

Smith, HV, Caccio, SM, Tait, A, et al, 2006: Tools for investigating the environmental transmission of Cryptosporidium and Giardia infections in humans. Trends Parasitol. 4:160-81.

Smith, HV, Nichols, RAB, 2007: Cryptosporidium. In: Simjee, S. (Ed.), Food borne Diseases. Humana Press, Totowa. NJ, USA.

Smith, JJ, Gunasekera, TS, Barardi, CR, et al, 2004: Determination of Cryptosporidium parvum oocyst viability by fluorescence in situ hybridization using a ribosomal RNAdirected probe. J. Appl. Microbiol. 96:409-17. Sponseller, JK, Griffiths, JK, Tzipori, S, 2014: The evolution of respiratory cryptosporidiosis: Evidence for transmission by inhalation. Clin. Microbiol. Rev. 27, 3: 575-86

Sunnotel, O, Lowery, CJ, Moore, JE, et al, 2006: Under the microscope: Cryptosporidium. Letter Appl. Microbiol. 42:7-14.

Tandon, N, Gupta, S, 2014: Cryptosporidiosis causing severe persistent diarrhea in a patient with multiple myeloma: A Case report and brief review of literature. Indian J. Med. Paediatr. Oncol. 35, 1:93-5.

Thompson, RC, Olson, ME, Zhu, G, et al, 2005: Cryptosporidium and cryptosporidiosis. Adv. Parasitol.59:77-158.

Traversa, D, 2010: Evidence for a new species Cryptosporidium infecting tortoises: Cryptosporidium ducismarci. Parasite Vector
3:21-9.

Tzipori, S, Ward, H, 2002: Cryptosporidiosis: biology, pathogenesis and disease. Microb. Infect. 4:1047-58.

Waldron, LS, Cheung-Kwok-Sang, C, Power, ML, 2010: Wildlife-associated Cryptosporidium fayeri in human, Australia. Emer. Infect. Dis. 16:100-8.

Woods, KM, Upton, SJ, 1998: Efficacy of select antivirals against Cryptosporidium parvum in vitro. FEMS Microbiol. Lett. 168:5963.

Xian-ming, C, Janet, SK, Eithly, C, Paya, V, et al, 2002: Solid organ transplantation in HIV- infected patient N. Engl. J. Med. 22:234-9.

Xiao, L, Fayer, R, 2008: Molecular characterization of species and subtypes of Cryptosporidium and Giardia and assessment of zoonotic transmission. Int. J. Parasitol. 38:123955.

Xiao, L, Fayer, R, Ryan, U, et al, 2004: Cryptosporidium Taxonomy: Recent Advances and Implications for Public Health. Clin. Microbiol. Rev. 17:72-97.

Xiao, L, Feng, Y, 2008: Zoonotic Cryptosporidiosis. FEMS Immunol. Med. Microbiol. 52:309-23.

Yoder, JS, Beach, MJ, 2010: Cryptosporidium surveillance and risk factors in the United States. Exp. Parasitol. 124:31-9.

Youssef, FG, Adib, I, Riddle, MS, et al, 2008: A review of cryptosporidiosis in Egypt. J. Egypt. Soc. Parasitol. 38:9-28.

Zaidah, AR, Chan, YY, Asma, HS, et al, 2008:Detection of Cryptosporidium parvum in HIV-infected patients in Malaysia using a molecular approach.Southeast Asian J. Trop. Med. Pub. Hlth. 39:511-6.

Zardi, EM, Picardi, A, Afeltra, A, 2005: Treatment of cryptosporidiosis in immunocompromised hosts. Chemotherapy 51:193-6.

Zhou, R, Hu, G, Liu, J, Gong, AY, et al, 2009: NF-kappaB p65-dependent transactivation of miRNA genes following Cryptosporidium parvum infection stimulates epithelial cell immune responses. PLoS Pat. 5:12-8. 